\title{
Adesão a higienização das mãos por estudantes e profissionais da saúde: revisão integrativa
}

\author{
Adherence to hand hygiene by students and health professionals: systematic review
}

Adhesión a la higiene de manos por parte de estudiantes y profesionales de la salud: revisión sistemática

Ane Kássia de Carvalho Barbosa1*, Ayana Rocha Porto Mousinho1, Larruama Soares Figueiredo

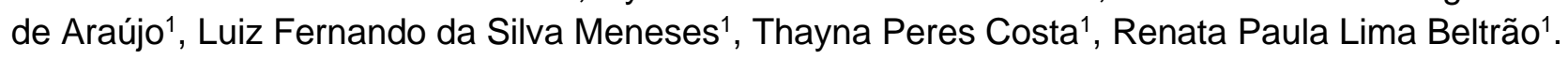

\section{RESUMO}

Objetivo: Pesquisar na literatura científica a adesão a higienização das mãos por estudantes e profissionais da saúde. Métodos: Foi realizada uma revisão sistemática nas bases de dados indexadas à Biblioteca Virtual em Saúde (BVS) e no Scientific Electronic Library Online (Scielo), usando como critério de inclusão artigos originais, publicados no período de 2015 a 2020, nos idiomas inglês e português, e como critérios de exclusão, artigos duplicados e aqueles sem relação com o tema. Resultados: Compõem essa pesquisa 13 artigos, nos quais foi possível averiguar que existem divergências siginificativas quanto a adesão a higienização das mãos por estudantes e profissionais de saúde. Considerações finais: É válido destacar que os estudantes e profissionais de saúde se comportam de forma diferente no tocante as medidas de adesão á higienização da mãos, foi possível identificar que os acadêmicos apresentam certa resistência a aderir e praticar tais precauções, quando comparado com os profissionais de saúde que possuem pelo menos o nível de graduação. Medidas envolvendo formação adequada, treinamento para execução técnica da $\mathrm{HM}$ e a realização de campanhas e oficinas periódicas funcionam como medidas para fortalecimento dessa attitude.

Palavras-chave: Segurança do paciente, Higienização das mãos, Medicina.

\begin{abstract}
Objective: Search in the scientific literature the adherence to hand hygiene by students and health professionals. Methods: A systematic review was carried out in the databases indexed to the Virtual Health Library (VHL) and in the Scientific Electronic Library Online (Scielo), using original articles published in the period from 2015 to 2020, in English and Portuguese, as inclusion criteria. Portuguese, and as exclusion criteria, duplicate articles and those unrelated to the topic. Results: This research comprises 13 articles, in which it was possible to ascertain that there are significant divergences regarding adherence to hand hygiene by students and health professionals. Conclusion: It is worth noting that students and health professionals behave differently when it comes to measures of adherence to hand hygiene, it was possible to identify that academics have a certain resistance to adhere to and practice such precautions, when compared with health professionals who have at least the level of graduation. Measures involving adequate training, training for technical execution of HM and periodic campaigns and workshops work as measures to strengthen this attitude.
\end{abstract}

Keywords: Patient safety, Hand hygiene, Medicine.

${ }^{1}$ Faculdade de Ciências Humanas, Exatas e de Saúde do Piauí (FAHESP/IESVAP), Parnaíba-PI.

*E-mail: ane.kassia@hotmail.com

SUBMETIDO EM: 4/2020

ACEITO EM:5/2020

PUBLICADO EM: 8/2020

REAS/EJCH | Vol.Sup.n.58 | e3775 | DOI: https://doi.org/10.25248/reas.e3775.2020 Página 1 de 11 


\section{RESUMEN}

Objetivo: Buscar en la literatura científica la adhesión a la higiene de manos por parte de estudiantes y profesionales de la salud. Métodos: Se realizó una revisión sistemática en las bases de datos indexadas a la Biblioteca Virtual en Salud (BVS) y en la Biblioteca Electrónica Científica en línea (Scielo), utilizando artículos originales publicados en el período de 2015 a 2020, en inglés y portugués, como criterios de inclusión. Portugués, y como criterio de exclusión, artículos duplicados y aquellos no relacionados con el tema. Resultados: Esta investigación comprende 13 artículos, en los cuales fue posible determinar que existen divergencias significativas con respecto a la adherencia a la higiene de manos por parte de estudiantes y profesionales de la salud. Conclusión: Vale la pena señalar que los estudiantes y los profesionales de la salud se comportan de manera diferente cuando se trata de medidas de adherencia a la higiene de las manos, fue posible identificar que los académicos tienen cierta resistencia a adherirse y practicar tales precauciones, en comparación con los profesionales de la salud que tener al menos el nivel de graduación. Las medidas que involucran capacitación adecuada, capacitación para la ejecución técnica de HM y campañas y talleres periódicos funcionan como medidas para fortalecer esta actitud.

Palabras clave: Seguridad del paciente, Higiene de manos, Medicina.

\section{INTRODUÇÃO}

É notório que a Higienização das Mãos (HM) é uma medida simples, de baixo custo, mas com um potencial imensurável no tocante a redução de Infecções Relacionadas a Assistência à Saúde (IRAS), sendo imprescindível o debate e a contemplação desta temática pelos estudantes e profissionais da área da saúde. Assim, tal prática é tida como um importante indicador de qualidade dos serviços de saúde para a segurança do paciente, uma vez que é considerada uma medida individual mais simples e eficaz para prevenir e controlar as infecções relacionadas à assistência à saúde e a disseminação de microrganismos multirresistentes (PRADO MF, et al., 2013).

A limpeza das mãos é um tópico complexo, multifatorial, que precisa ser persistentemente trabalhado com a equipe de saúde em seu conjunto, ressaltando os pontos comportamentais e pessoais que estão vigorosamente relacionados ao assunto, de modo a alcançar a sua melhoria e, sobretudo, a manutenção em níveis aceitáveis de segurança para o cuidado de saúde prestado (OLIVEIRA AC, et al., 2016).

A Higienização das Mãos (HM) é uma prática universalmente reconhecida como medida primacial e preventiva no controle de Infecções Relacionadas à Assistência à Saúde (IRAS), que além de acometer os pacientes, intimida também os profissionais dos serviços de saúde (BRASIL, 2009). Em razão da importância desse simples procedimento, foi instituído pela Organização Mundial de Saúde (OMS) o dia 05 de maio como o Dia Mundial de Higienização das Mãos, para que os serviços de saúde possam promover ações educativas viabilizando a conscientização dos profissionais de saúde, do governo e dos administradores hospitalares sobre a higienização das mãos, apontando os males da não realização da prática (FARIAS MEL, et al., 2019).

Dentre as causas prováveis da ausência de adesão à HM, pode-se considerar o acontecimento de IRAS, que afeta em torno de 1,4 milhões de pacientes por ano no mundo, estendendo o tempo de internação hospitalar, provocando a multiplicação da resistência antimicrobiana, a incapacidade a longo prazo, despesas elevadas para o sistema de saúde, pacientes e familiares e aumento da mortalidade (FARIAS MEL, et al., 2019).

A Portaria no 2.616/1998 do Ministério da Saúde define a infecção hospitalar como aquela que é obtida após admissão do paciente e que se alastra durante a internação ou após a alta, estando integralmente ligada com o internamento ou com os procedimentos hospitalares realizados. Contudo, a prevenção e o controle das infecções ainda estão dentre os problemas que mais aumentam em território nacional brasileiro, ocasionando gastos exorbitantes, visto que o valor despendido em pacientes com infecção é cerca de três vezes maior em relação aos pacientes sem infecção, ocasionando danos materiais e imateriais a todas as esferas da sociedade (SANTANA-CAIRES M, et al., 2016). 
A higienização das mãos dos profissionais da saúde demonstra um dos eixos preferenciais na melhoria de deveres seguros e alcance de maior qualidade assistencial. Dessa forma, tanto na esfera nacional como internacional, pesquisadores, gerentes/gestores e os próprios profissionais que agem na área da saúde têm examinado, discutido, elaborado e executado mecanismos para que esse método seja exercido nos momentos necessários e de maneira apropriada em todos os pontos assistenciais (DERHUM FM, et al., 2018).

Apesar de sua importância comprovada, as taxas de aprovação às medidas de higienização das mãos ainda são decadentes. Por outra perspectiva, estudos têm evidenciado que medidas de educação são fundamentais em aumentar essa adesão e em reduzir as taxas de infecção (ROMERO DMP, et al., 2019).

Segundo os dados do Center for Disease Control and Prevention, dez em cada cem pacientes hospitalizados em países em desenvolvimento obtêm ao menos uma Infecção Relacionada à Assistência à Saúde (IRAS), o que faz aumentar de forma aguda e rápida, quase que imediata, os números da mortalidade e os gastos dos sistemas de saúde, refletindo indicadores de saúde negativos.

Mesmo diante disso, essa é uma realidade fácil de ser modificada, tendo em vista que, quando as unidades de assistência à saúde e seus multiprofissionais têm conhecimento e noção do problema a qual enfrentam e passam a aderir as medidas profiláticas, há uma redução de até $70 \%$ de algumas IRAS, como por exemplo das infecções com porta de entrada sanguínea (GUARANA CVPS, et al., 2019).

Assim sendo, a prática da higienização das mãos é uma recomendação pioneira, efetiva e de pequeno custo, impactando na essência da assistência e na proteção do paciente. Para isso, a prática de HM deve ser incentivada e incluída nas atividades educativas do processo de trabalho das instituições de saúde, bem como em programas de monitorização e acompanhamento da adesão (FARIAS MEL, et al., 2019).

Com a finalidade de contribuir para as pesquisas sobre a adesão a higienização das mãos por estudantes e profissionais da saúde, justifica-se este estudo. Assim, surge a seguinte problemática: Como se dá a adesão a higienização das mãos por estudantes e profissionais da saúde. Para solucionar tal indagação, traçou-se o seguinte objetivo: Pesquisar na literatura científica a adesão a higienização das mãos por estudantes e profissionais da saúde. A escolha da temática deu-se em virtude da escassez de pesquisas que avaliam a adesão a higienização das mãos por estudantes e profissionais da saúde.

\section{MÉTODOS}

Trata-se de um estudo de revisão integrativa, conduzida de acordo com os Principais Itens para Relatar Revisões sistemáticas e Meta-análises (PRISMA), realizando buscas nas bases de dados indexadas à Biblioteca Virtual em Saúde (BVS) e no Scientific Electronic Library Online (Scielo).

Foram determinados como critérios de inclusão artigos originais disponíveis na íntegra, que tenham sido publicados no período entre 2015 a 2020, nos idiomas inglês e português, e como critérios de exclusão, artigos duplicados e sem relação com o tema.

As buscas foram realizadas utilizando como descritores os seguintes termos: "Higienização das mãos and Medicina", "Segurança do paciente and Higienização das mãos".

Após realizada a análise dos artigos coletados nas bases de dados, foram encontrados 44 , dentro os quais 3 na base BVS e 41 na base Scielo. Desse total, foi realizada uma análise baseada nos critérios de exclusão e inclusão.

Após realizado o processo de triagem, foram excluídos 18 artigos, restando 23 para avaliação de conteúdo, após esta avaliação, se enquadraram dentro dos critérios de inclusão apenas 13 artigos, os quais compuseram essa pesquisa (Figura 1). 
Figura 1 - Fluxograma de seleção dos artigos que integram a pesquisa.
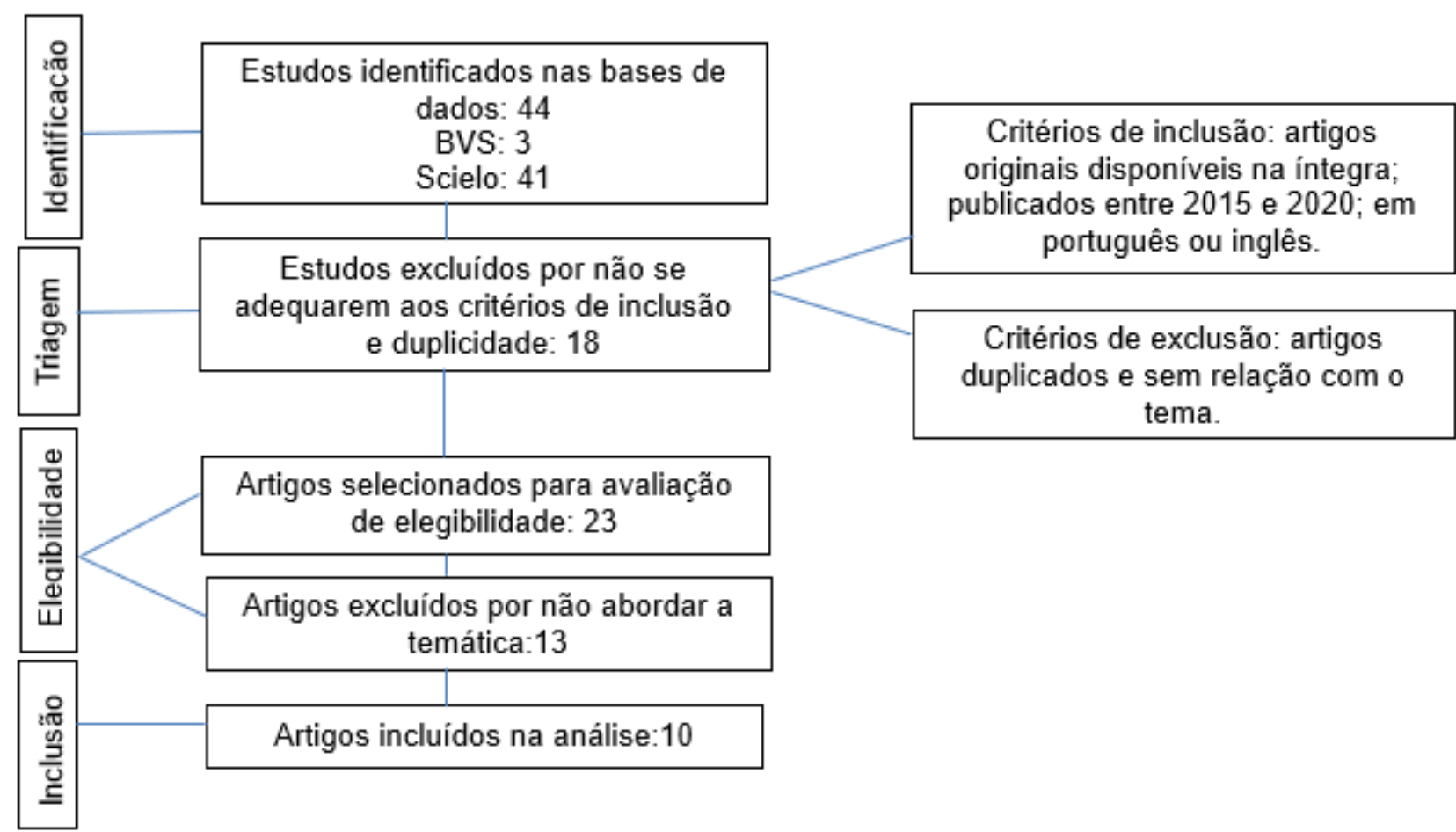

Fonte: Barbosa AKC, et al., 2020.

\section{RESULTADOS}

Foram utilizados artigos que discorriam sobre a adesão a higienização das mãos por estudantes e profissionais da saúde: 1) os riscos e os benefícios; 2) as consequências e as recomendações sobre a adesão a higienização das mãos. Apenas 13 artigos se enquadraram dentro dos critérios de inclusão. Para melhor compreensão, os estudos foram organizados por descrição de algumas características, tais como: autores, ano de publicação, periódico, tipo de estudo, objetivos e interpretação do estudo, como pode ser observado no Quadro 1. 


\section{Revista Eletrônica Acervo Saúde / Electronic Journal Collection Health ｜ ISSN 2178-2091}

Quadro 1 - Caracterização de artigos incluídos na pesquisa. Parnaíba, Brasil 2020.

\begin{tabular}{|c|c|c|c|c|}
\hline Autor/Ano & Periódico & $\begin{array}{l}\text { Tipo de } \\
\text { Estudo }\end{array}$ & Objetivo & Interpretação do Estudo \\
\hline $\begin{array}{c}\text { Romero DMP, } \\
\text { et al. (2019) }\end{array}$ & JBP & $\begin{array}{c}\text { Quase } \\
\text { experimental }\end{array}$ & $\begin{array}{l}\text { Avaliar os efeitos da implementação de } \\
\text { um programa de educação sobre HM e } \\
\text { a adesão a essa prática entre } \\
\text { profissionais de uma UTI. }\end{array}$ & $\begin{array}{l}\text { Baseado em } 959 \text { observações, houve um aumento nas taxas de } \\
\text { adesão à higienização das mãos de } 31,5 \% \text { no período basal para } \\
65,8 \% \text { no período de intervenção e para } 83,8 \% \text { no período pós } \\
\text { intervenção, representando uma razão de prevalência } 2,09 \text { e } 2,66 \\
\text { maior que o período basal, respectivamente }(p<0,001) \text {. }\end{array}$ \\
\hline $\begin{array}{l}\text { Santana-Caires } \\
\text { M, et al. (2016) }\end{array}$ & $\begin{array}{l}\text { Revista } \\
\text { Brasileira de } \\
\text { Educação } \\
\text { Médica }\end{array}$ & Transversal & $\begin{array}{l}\text { Avaliar a conduta e o conhecimento } \\
\text { dos estudantes de medicina do quinto } \\
\text { e sexto ano da Faculdade de Medicina } \\
\text { da Universidade Federal da Bahia. }\end{array}$ & $\begin{array}{l}\text { Dos } 160 \text { estudantes que responderam o questionário, } 76 \% \text { dos } \\
\text { entrevistados auto avaliaram seu conhecimento sobre normas de } \\
\text { higienização como "excelente" e "bom", contudo, apenas } 50 \% \\
\text { realizam a higienização das mãos antes e após contato com o } \\
\text { paciente. Cerca de } 55 \% \text { não concordam com a criação de um } \\
\text { novo componente curricular específico para essa temática. } \\
\text { Observam-se resultados divergentes quanto ao conhecimento } \\
\text { dos estudantes sobre normas de higiene e à sua conduta na } \\
\text { prática médica. }\end{array}$ \\
\hline $\begin{array}{l}\text { Guaraná CVPS, } \\
\text { et al. } \\
(2019)\end{array}$ & $\begin{array}{l}\text { Revista } \\
\text { Brasileira de } \\
\text { Educação } \\
\text { Médica }\end{array}$ & Transversal & $\begin{array}{l}\text { Avaliar os conhecimentos, habilidades } \\
\text { e atitudes de estudantes do quarto e } \\
\text { oitavo período do curso de medicina } \\
\text { sobre segurança do paciente por meio } \\
\text { de simulação. }\end{array}$ & $\begin{array}{l}\text { Participaram do estudo } 42 \text { estudantes, sendo } 24 \text { do quarto } \\
\text { período e } 18 \text { do oitavo. Nenhum estudante identificou todos os } \\
\text { seis riscos. No geral, os alunos apresentaram baixo desempenho, } \\
\text { tendo identificado em média de dois a três riscos à segurança do } \\
\text { paciente, dentre eles os problemas de higienização das mãos por } \\
6 \text { alunos (14\%). }\end{array}$ \\
\hline $\begin{array}{l}\text { Silva VD, et al. } \\
\qquad(2017)\end{array}$ & Revista Rene & Transversal & $\begin{array}{l}\text { Verificar a habilidade de acadêmicos } \\
\text { de enfermagem e medicina } \\
\text { relacionados à técnica da HM. }\end{array}$ & $\begin{array}{l}\text { Em geral, } 35,7 \% \text { dos acadêmicos de enfermagem e } 15,1 \% \text { dos } \\
\text { acadêmicos de medicina empregaram a técnica de higienização } \\
\text { das mãos com álcool gel a } 70 \% \text {. Seguindo os oito passos } \\
\text { recomendados os passos menos realizados pelos acadêmicos de } \\
\text { enfermagem foram "esfregar palma com dorso", } 46,4 \% \text { não } \\
\text { realizaram, e da medicina "esfregar costas dos dedos sobre as } \\
\text { palmas", } 63,6 \% \text {. Nenhum acadêmico conseguiu contemplar todas } \\
\text { as áreas. }\end{array}$ \\
\hline
\end{tabular}

REAS/EJCH | Vol.Sup.n.58 | e3775 | DOI: https://doi.org/10.25248/reas.e3775.2020 Página 5 de 11 


\section{Revista Eletrônica Acervo Saúde / Electronic Journal Collection Health ｜ ISSN 2178-2091}

\begin{tabular}{|c|c|c|c|c|}
\hline $\begin{array}{l}\text { Skodova M, et } \\
\text { al. } \\
(2015)\end{array}$ & $\begin{array}{l}\text { Revista Latino- } \\
\text { Americana de } \\
\text { Enfermagem }\end{array}$ & $\begin{array}{l}\text { Descritivo } \\
\text { Transversal }\end{array}$ & $\begin{array}{l}\text { Conhecer a situação real da HM dos } \\
\text { estudantes de enfermagem e medicina } \\
\text { matriculados na Faculdade de } \\
\text { Medicina do Campus de Badajoz da } \\
\text { Universidade de Extremadura (UEX). }\end{array}$ & $\begin{array}{l}\text { Avaliaram-se } 546 \text { alunos, } 73,8 \% \text { da graduação em medicina e } \\
26,2 \% \text { da enfermagem. As áreas das mãos com correta } \\
\text { distribuição de sabão foram as palmas }(92,9 \%) \text {, as áreas não } \\
\text { esfregadas corretamente foram os polegares }(55,1 \%) \text {. Em ambas } \\
\text { as mãos, a higienização foi muito boa em } 24,7 \% \text {, boa em } 29,8 \% \text {, } \\
\text { regular em } 25,1 \% \text { e má em } 20,3 \% \text {. Os piores foram os homens, } \\
\text { os estudantes de enfermagem e os estudantes de primeiro ano } \\
\text { de escola }\end{array}$ \\
\hline $\begin{array}{l}\text { Zottele C, et al. } \\
\qquad(2017)\end{array}$ & $\begin{array}{l}\text { Revista da } \\
\text { Escola de } \\
\text { Enfermagem } \\
\text { da USP }\end{array}$ & $\begin{array}{l}\text { Quantitativa } \\
\text { com } \\
\text { delineamento } \\
\text { longitudinal }\end{array}$ & $\begin{array}{l}\text { Analisar a adesão à } \mathrm{HM} \text { dos } \\
\text { profissionais de saúde em uma unidade } \\
\text { de pronto-socorro. }\end{array}$ & $\begin{array}{l}\text { Participaram do estudo } 59 \text { profissionais da saúde. A taxa de } \\
\text { conformidade foi de } 54,2 \% \text {. Enfermeiros e fisioterapeutas } \\
\text { mostraram uma taxa de adesão de } 66,6 \% \text { e médicos residentes, } \\
41,3 \% \text {. Quando a conformidade foi comparada entre categorias } \\
\text { profissionais, os enfermeiros apresentaram maior adesão do que } \\
\text { os médicos residentes. }\end{array}$ \\
\hline $\begin{array}{l}\text { Farias MEL, et } \\
\text { al. (2019) }\end{array}$ & $\begin{array}{c}\text { Revista } \\
\text { Eletrônica } \\
\text { Acervo Saúde }\end{array}$ & $\begin{array}{l}\text { Descritiva- } \\
\text { documental }\end{array}$ & $\begin{array}{l}\text { Analisar os efeitos das ações } \\
\text { educativas sobre adesão dos } \\
\text { profissionais de saúde à HM em } \\
\text { hospital universitário. }\end{array}$ & $\begin{array}{l}\text { Foram analisadas } 1.371 \text { oportunidades nas unidades de } \\
\text { internação no hospital. Realizada uma comparação dos registros } \\
\text { de observação direta da adesão à HM, considerando as } \\
\text { oportunidades nas quais os profissionais de saúde utilizaram } \\
\text { água e sabão ou álcool gel a } 70 \% \text { ou não aderiram à prática de } \\
\text { HM. A maioria dos profissionais não higienizou no momento } \\
\left.\text { indicado ( } x^{2}=14,544 ; \text { p valor }=0,0423\right) \text {. O comportamento dos } \\
\text { mesmos não mudou, tendo se mantido o hábito de não higienizar } \\
\text { as mãos nos cinco momentos básicos }\left(x^{2}=4,933 ; p \text { valor }=0,1768\right) \text {. }\end{array}$ \\
\hline $\begin{array}{l}\text { Souza LM, et al. } \\
\qquad(2015)\end{array}$ & $\begin{array}{l}\text { Revista } \\
\text { Gaúcha de } \\
\text { Enfermagem }\end{array}$ & $\begin{array}{l}\text { Transversal } \\
\text { analítico }\end{array}$ & $\begin{array}{l}\text { Identificar a adesão dos profissionais } \\
\text { de saúde de uma Unidade de Terapia } \\
\text { Intensiva aos cinco momentos de HM. }\end{array}$ & $\begin{array}{l}\text { Em } 446 \text { (56,2\%) observações não ocorreu HM, ficando a taxa de } \\
\text { adesão em } 43,7 \% \text {. A maior adesão a HM foi dos fisioterapeutas } \\
(53,5 \%) \text {, a menor, dos técnicos de enfermagem }(29,2 \%) \text {. As } \\
\text { indicações com menor adesão à HM foram "antes do contato com } \\
\text { o paciente" }(18,4 \%) \text { e "antes de procedimento asséptico" }(20,9 \%) \text {. }\end{array}$ \\
\hline
\end{tabular}

REAS/EJCH | Vol.Sup.n.58 | e3775 | DOI: https://doi.org/10.25248/reas.e3775.2020 Página 6 de 11 


\section{Revista Eletrônica Acervo Saúde / Electronic Journal Collection Health ｜ ISSN 2178-2091}

\begin{tabular}{|c|c|c|c|c|}
\hline $\begin{array}{l}\text { Oliveira AC, et } \\
\text { al. } \\
(2016)\end{array}$ & $\begin{array}{c}\text { Revista Visa } \\
\text { em Debate }\end{array}$ & $\begin{array}{l}\text { Observacional, } \\
\text { seccional com } \\
\text { abordagem } \\
\text { quantitativa }\end{array}$ & $\begin{array}{l}\text { Avaliar a conformidade e não } \\
\text { conformidade das práticas de adesão à } \\
\text { HM com linhas vasculares na } \\
\text { prevenção de infecção de corrente } \\
\text { sanguínea relacionada ao cateter } \\
\text { venoso central de curta permanência. }\end{array}$ & $\begin{array}{l}\text { A taxa de adesão à } \mathrm{HM} \text { foi de } 35,2 \% \text {, sendo os fatores } \\
\text { facilitadores referidos pelos profissionais: conscientização da } \\
\text { transmissão cruzada, proteção individual, disponibilidade de } \\
\text { material. Como empecilhos, a falta de treinamento dos } \\
\text { profissionais, a indisponibilidade de equipamento e situações de } \\
\text { emergência. }\end{array}$ \\
\hline $\begin{array}{l}\text { Graveto JMGN, } \\
\text { et al. } \\
\text { (2018) }\end{array}$ & $\begin{array}{l}\quad \text { Revista } \\
\text { Brasileira de } \\
\text { Enfermagem }\end{array}$ & $\begin{array}{l}\text { Revisão } \\
\text { integrativa de } \\
\text { Literatura }\end{array}$ & $\begin{array}{l}\text { Conhecer a adesão dos enfermeiros ao } \\
\text { procedimento de HM e identificar } \\
\text { estratégias de atuação de forma a } \\
\text { aumentar a mesma. }\end{array}$ & $\begin{array}{l}\text { Estudos demonstram o aumento da adesão a HM por parte dos } \\
\text { enfermeiros de } 42,9 \% \text { para } 61,4 \% \text { após intervenção específica } \\
(p<0,001) \text {. }\end{array}$ \\
\hline $\begin{array}{l}\text { Derhun FM, et } \\
\text { al. } \\
(2018)\end{array}$ & $\begin{array}{l}\text { Revista de } \\
\text { Enfermagem }\end{array}$ & $\begin{array}{l}\text { Quantitativo, } \\
\text { descritivo- } \\
\text { exploratório }\end{array}$ & $\begin{array}{l}\text { Verificar o conhecimento de } \\
\text { enfermagem sobre a fricção } \\
\text { antisséptica das mãos com preparação } \\
\text { alcoólica. }\end{array}$ & $\begin{array}{l}\text { Para as questões sobre a cobertura das mãos com o produto e } \\
\text { necessidade de secagem após fricção o conhecimento foi } \\
\text { satisfatório ( } 92,6 \% \text { e } 85,2 \% \text {, respectivamente), mas para o tempo } \\
\text { mínimo do procedimento e necessidade das mãos estarem } \\
\text { previamente secas foi insatisfatório (18,5\% e } 59,3 \% \text {, } \\
\text { respectivamente). }\end{array}$ \\
\hline $\begin{array}{c}\text { Barbosa FS } \\
(2019)\end{array}$ & $\begin{array}{c}\text { Brazilian } \\
\text { Journal of } \\
\text { health Review }\end{array}$ & $\begin{array}{l}\text { Revisão de } \\
\text { literatura com } \\
\text { pesquisa de } \\
\text { campo, } \\
\text { descritivo- } \\
\text { qualitativo }\end{array}$ & $\begin{array}{l}\text { Conhecer e levantar dados sobre a } \\
\text { temática que envolve a equipe } \\
\text { multidisciplinar de saúde no que diz } \\
\text { respeito a prevenção de infecções } \\
\text { hospitalares numa unidade hospitalar. }\end{array}$ & $\begin{array}{l}\text { Os números levantados na pesquisa de campo demonstram uma } \\
\text { baixa adesão para a rotina de HM. Para controlar as IRAS, a HM } \\
\text { deve ser aderida pelo maior número possível de profissionais, } \\
\text { deve ser buscada com informação que pode ser implementada } \\
\text { com cartazes nas pias e nos pontos de álcool gel e treinamento } \\
\text { semanal das equipes profissionais, utilizando técnicas de } \\
\text { abordagem agradáveis que sensibilizem o profissional para as } \\
\text { boas práticas de assistência à saúde. }\end{array}$ \\
\hline $\begin{array}{c}\text { Freitas TSC, } \\
(2017)\end{array}$ & $\begin{array}{l}\text { Revista da } \\
\text { Universidade } \\
\text { Federal } \\
\text { Fluminense }\end{array}$ & $\begin{array}{l}\text { Qualitativa, } \\
\text { descritiva }\end{array}$ & $\begin{array}{l}\text { Implementar um plano de ação } \\
\text { fundamentado na estratégia } \\
\text { multimodal da OMS, desenvolvendo } \\
\text { ideias inovadoras para a promoção da } \\
\text { HM dos profissionais de saúde. }\end{array}$ & $\begin{array}{l}\text { Foram realizadas entrevistas onde se destacou a educação } \\
\text { permanente como uma estratégia fundamental e o programa de } \\
\text { reconhecimento como um recurso importante de estímulo ao } \\
\text { profissional. A implementação das estratégias inovadoras estão } \\
\text { inseridas num plano de ação fundamentado na estratégia } \\
\text { multimodal que é o produto desta pesquisa com enfoque na } \\
\text { adesão da HM bem sucedida e sustentável. }\end{array}$ \\
\hline
\end{tabular}

Fonte: Barbosa AKC, et al., 2020.

REAS/EJCH | Vol.Sup.n.58 | e3775 | DOI: https://doi.org/10.25248/reas.e3775.2020 Página 7 de 11 
Com relação ao ano de publicação, como apresentado no Quadro 1, os anos de 2019 e 2017 concentraram quatro artigos. Em seguida os anos de 2018 e 2016, com três publicações cada um e o ano de $2015 \mathrm{com}$ duas publicações. Com relação ao tipo de estudo, os artigos em sua maioria são oriundos de pesquisas originais com o incremennto de dois artigos com abordagem de revisão integrativa de literatura para finalidade de embasamento teórico. As pesquisas originais foram realizadas diretamente com estudantes e/ou profissionais de saúde ou bancos de informações, são estudos do tipo descritivo, exploratório, observacional, documental, transversal e com delineamento longitudinal. Os periódicos de origem dos artigos, grande parte são da área da medicina e saúde, com artigos nacionais e internacionais, reafirmando mais uma vez, a relevância da temática em estudo e do rigor metodológico que os artigos se encontram (Quadro 1).

\section{DISCUSSÃO}

A HM das mãos tem por finalidade remover sujidade, material orgânico e/ou microrganismos, precavendo sua propagação cruzada. Pode acontecer de quatro maneiras: higienização simples das mãos (com água e sabão); higienização antisséptica das mãos; atrito antisséptica das mãos (desde que não haja sujidade visível) e antissepsia cirúrgica das mãos (SOUZA LM, et al., 2015).

No ano de 1846, Ignaz Semmelweis ratificou a importância da lavagem das mãos, diminuindo o índice de contaminação puerperal, ao inserir o uso de solução clorada, após autópsia e antes de se efetuar partos. No mesmo ano, Oliver Wendell Holmes, para a moderação de infecções, da mesma forma, efetivou a lavagem das mãos. Prontamente, o conhecimento sobre o efeito da higienização das mãos para precaver infecções vem sendo erguido tradicionalmente e evidenciado com o aperfeiçoamento dos parâmetros científicos, sobretudo, no século XX. Contudo, a adversidade do apoio a essa medida ainda permanece atualmente (FREITAS TSC, 2017).

A seguridade do paciente (SP) traz a discussão muitas atitudes e saberes dos profissionais de saúde durante o seu atendimento voltado ao paciente com o intuito de prevenir eventuais erros antes que eles causem danos no decorrer da assistência prestada. O cuidado com a SP data de 1855, quando Florence Nightingale, uma enfermeira britânica, recomendou que a higiene dos hospitais surpreenderia diretamente a assistência oferecida aos seus pacientes.

Em 1910, um cirurgião americano, Ernest Codman, produziu os "padrões mínimos", que objetivaram à melhoria permanente dos serviços de saúde. Em 1999, o Instituto de Medicina difundiu o relatório "Errar É Humano", que, além de expor as falhas dos serviços de saúde, colocou este tema na pauta da Organização Mundial da Saúde (OMS) e das políticas de saúde de diversos países.

No Brasil, em 1994, lançou-se o programa de acreditação para o aperfeiçoamento da qualidade hospitalar. Em 2011, o Ministério da Saúde (MS) publicou um programa em que contemplava os municípios e os seus serviços de saúde de acordo com o seu dinamismo na qualidade da saúde oferecida (GUARANA CVPS, et al., 2019).

Foi colocado como obrigatório que, em todos os serviços de saúde do país, a constituição de núcleos de segurança do paciente (NSP) fossem designadas, com os objetivos de definir e implementar um plano de segurança do paciente (PSP), segundo a necessidade e as especificidades do serviço (COSTA EAM, et al,. 2020).

Por conseguinte, enfatiza-se que a Infeção Associada aos Cuidados de Saúde (IACS) consiste em um problema existente e grave no âmbito da qualidade do prestamento de precauções, podendo ser causada por agentes infeciosos de origem endógena (pele, nariz, trato gastrointestinal, entre outros) ou exógena, sendo as mãos dos profissionais de saúde o transporte de transmissão mais frequente (GRAVETO JMGN, et al., 2018).

No entanto, de acordo com o embasamento teórico o prefácio ao tema higienização e biossegurança ocorre em um período distante e dissociado da prática clínica, obstaculizando a adesão efetiva dos estudantes (SANTANA-CAIRES M, et al., 2016). 
Em meados do século XXI mesmo com o advento de novas tecnologias e crescimento do entendimento clínico, experimenta-se a expansão veloz e desenfreada de bactérias altamente resistentes e que causam infecções capazes de levar o indivíduo a decesso (BARBOSA FS, 2019).

A cautela em saúde deve ser transportada com consciência, comprometimento profissional e dever assumido para com o outro, na diligência de sua vitalidade e proteção, livre de danos evitáveis, como determinam os códigos de ética das profissões da área da saúde (SOUZA LM, et al., 2015).

Dessa forma, o Guideline do Centers for Disease Control and Prevention (CDC) apresenta cuidados direcionados ao ambiente, aos objetos e aos profissionais de saúde; nessa perspectiva, a higienização das mãos é recomendada como a medida isolada mais eficaz para a prevenção e controle de infecções. Com isso, têm-se um dos pilares da segurança do paciente direcionado a higienização das mãos é reconhecida por um órgão competente na área, tal como a Organização Mundial da Saúde (OMS) (FERNANDES, DR, et al., 2019).

Nessa perspectiva, vale salientar que o contato das mãos é uma das principais formas de transmissão de microrganismos de uma pessoa para outra, sendo assim, um importante foco para o desenvolvimento de doenças e agravos a saúde. Dados mundiais comprovam que de 2 a 3 milhões de mortes em todo o mundo têm como responsável a diarreia, facilmente prevenida com a antissepsia das mãos.

Todavia, o uso de adornos (anéis, pulseiras, relógios etc.) durante o processo de higienização das mãos oferece maior risco de manter a permanência constante nas mãos de bacilos Gram negativos e $S$. aureus, patógenos comuns em infecções nosocomiais (SANTANA-CAIRES M, et al., 2016).

Entretanto, é mencionado na literatura que, mesmo tendo entendimento sobre a indispensabilidade e magnitude da $\mathrm{HM}$, os profissionais de saúde a efetivam com menor frequência e por um menor intervalo de tempo do que o indicado (OLIVEIRA FJ, et al., 2016).

Em um estudo observado, mostrou-se que a adesão dos profissionais da saúde à prática de HM mediante a educação contínua é baixa e, devido a isso, é necessário impulsionar a prática regularmente entre esses profissionais, reforçando a magnitude da mesma ser realizada nos cinco momentos para a HM conforme é proposto pela OMS: antes do contato com paciente, antes da realização de procedimentos invasivos, após o risco de exposição a fluidos corporais, após o contato com paciente e após o contato com as áreas próximas ao paciente (FARIAS MEL, 2019).

É contemplável ressaltar que dentre os fatores que contribuem para a Segurança do Paciente durante sua assistência de saúde e que inclusive é uma das metas da Organização Mundial de Saúde é a higiene das mãos para prevenir infecção e que a partir do momento que o acadêmico de enfermagem e de medicina se graduam sem realizar adequada essa técnica estamos colocando em risco a assistência de nossa clientela (SILVA VD, et al., 2017).

A partir dos relatos de propagação de microrganismos pelas mãos dos profissionais e de baixas taxas de adesão à $\mathrm{HM}$, surge a premência de monitorar estas práticas executadas pelos profissionais; é preciso detectar os motivos que os levam a não efetuarem a HM em conformidade com o proposto, para, assim, elaborar mecanismos que cresçam as taxas de adesão a esse procedimento, principalmente por meio de mudança de modelos comportamentais e culturais (OLIVEIRA FJ, et al., 2016).

De acordo com os achados referentes a qualificação das sete áreas, percebeu-se que os acadêmicos de enfermagem e medicina em seis áreas obtiveram percentual maior de erro, ou seja, de higienização das mãos não adequada. Com esse dado, fica evidente que os acadêmicos percorrem a graduação com déficit de habilidade e estudos na técnica correta da HM. Esse achado é consternador uma vez que as intervenções que contemplem a correta HM têm sido citadas como fatores importantes para a restringência de Infecções Relacionadas à Assistência à Saúde e progresso no conhecimento dos profissionais de como preveni-las (SILVA VD, et al., 2017). 
Em estudo realizado por Romero DMP, et al. (2019); ressalta-se que, por mais que houvesse uma preocupação do observador de se passar despercebido pela equipe durante os períodos de observação, é possível que sua presença tenha sido notada. Isso pode ter provocado uma adesão à higienização maior nos períodos de observação do que nos demais momentos em que ele não estivesse na UTI. Devido ao fato de o estudo ser conduzido em apenas uma UTI, com características epidemiológicas próprias, seus resultados não podem ser necessariamente ultrapassados para outras unidades.

Recomenda-se a adoção de cinco estratégias: disponibilidade de produtos para HM à beira do leito ou com o profissional de saúde, programas de educação do time de profissionais, lembretes (orais e verbais), feedback dos resultados e suporte da administração do hospital para o envolvimento do time (ROMERO DMP, et al., 2019).

A higienização das mãos no ambiente hospitalar pode ser realizada com solução alcoólica ou com água e sabonete líquido, sendo a última uma previsão da indicação em algumas situações específicas. Se a solução alcoólica for utilizada na apresentação em gel, deve ter uma concentração final de $70 \%$. A higienização simples com sabonete líquido e água tem a finalidade de remover microrganismos que colonizam as camadas superficiais da pele, assim como o suor, a oleosidade e as células mortas, retirando a sujidade propícia à permanência e à proliferação de microrganismos. Por outro lado, a solução alcoólica não proporciona remoção de sujidade, tendo a finalidade de reduzir a carga microbiana e substituir a higienização com água e sabão quando as mãos não tiverem sujidade visível, sendo que a OMS a recomenda como a principal forma de higienização rotineira das mãos em serviços de saúde (FERNANDES, DR, et al., 2019).

Independentemente de o tema HM ser bastante discutido, no decurso dos anos, a sua técnica e os produtos utilizados foram modificados. Isso pode ser averiguado nas preparações alcoólicas para fricção antisséptica das mãos, em permuta à convencional higienização com água e sabão, nas seguintes ocasiões: quando as mãos não estiverem obviamente sujas; anteriormente e após de tocar o paciente; após remover luvas; e, da mesma forma, antes do manuseio de medicação ou preparação de alimentos (DERHUN FM, et al., 2018; CHINDUMA AM, et al., 2017).

Por toda parte, a HM é reconhecida como um elemento crucial para a redução das incidências de infecções hospitalares. Conforme recomendado pela OMS, as pesquisas e publicações congregam-se na implantação de soluções hidroalcóolicas e avaliação do seu uso mediante distintas estratégias (SKODOVA M, et al., 2015).Uma dificuldade que é capaz de afetar na HM antes de procedimento asséptico é o uso de luvas, pois o profissional, por insciência, pode entender que ela substitui a HM. Todavia, salienta-se que o uso de luvas não substitui a HM, independentemente da indicação (SOUZA LM, et al., 2015).

A instrução sobre segurança do paciente nos currículos dos cursos de saúde apresenta-se fracionado, necessitando de aprofundamento e amplitude conceitual, como recomenda o guia da Organização Mundial da Saúde (GUARANA CVPS, et al., 2019). Portanto, continua sendo prioridade uma adequada formação e treinamento na correta execução técnica da $\mathrm{HM}$ e a realização de campanhas e oficinas periódicas (SKODOVA M, et al., 2015).

\section{CONSIDERAÇÕES FINAIS}

Sendo assim, uma adequada formação e treinamento na correta execução técnica da HM e a realização de campanhas e oficinas periódicas funcionam como medidas para fortalecimento dessa atitude. Nessa perspectiva, esmerar a HM deve ser uma prioridade das autoridades de saúde em todos os níveis, seja na graduação, na pós-graduação ou educação continuada, em que existe uma responsabilidade individual de cada profissional da saúde. Além disso, foi possível identificar que existem divergências significativas quanto a adesão a higienização das mãos por estudantes e profissionais de saúde. Foi possível identificar que os acadêmicos apresentam certa resistência a aderir e praticar tais precauções, quando comparado com os profissionais de saúde que possuem pelo menos o nível de graduação. Acredita-se que esta pesquisa possa contribuir para a busca de melhorias no âmbito da adesão a higienização das mãos por estudantes e profissionais de saúde, com a finalidade de se elevar ainda mais o conhecimento acerca da temática em questão e instigar a formulação de mais pesquisas nesse âmbito. 


\section{REFERÊNCIAS}

1. BRASIL - Portaria no 2616/MS/GM, de 12 de maio de 1998. Diário Oficial [da] República Federativa do Brasil, Brasília, DF, 13 mai 1998. Disponível em: < http://bvsms.saude.gov.br/bvs/saudelegis/gm/1998/prt2616_12_05_1998.html >. Acesso em 20 fev.

2. BRASIL. ANVISA. AGENCIA NACIONAL DE VIGILÂNCIA SANITÁRIA. Resolução da diretoria colegiada- RDC no 8, de 27 de fevereiro de 2009. Disponível em:< www.anvisa.gov.br/legis >. Acesso em: 20 fev.

3. BARBOSA FS. Higienização das mãos: Monitoração da adesão dos profissionais de saúde numa instituição pública da rede estadual do Rio de Janeiro: um desafio à administração do serviço de controle de infecção hospitalar. Brazilian Journal of Health Review, 2019; 2(2): 1323-1355.

4. CHINDUMA AM, et al. Portación de levaduras en manos de estudiantes de las carreras de Medicina y Enfermería de la Universidad de Talca, Chile. Bol. Micol. (Valparaiso En linea), 2017;32(2): 8-14.

5. COSTA EAM, et al. Segurança do paciente em serviços de saúde: uma análise na cidade de Salvador, Bahia. Revista SOBECC, São Paulo, 2020; 25(1): 17-24.

6. FARIAS MEL, et al. Adesão à higiene das mãos antes e após intervenções educativas do dia mundial para higienização das mãos em um hospital universitário. Revista Eletrônica Acervo Saúde, 2019; 11(16).

7. FERNANDES, DR, et al. Higiene das mãos: conhecimento e habilidade de cuidadores no transplante de célulastronco hematopoéticas. Rev. Bras. Enferm., 2019; 72(6): 1653-62.

8. DERHUN FM, et al. Uso da preparação alcoólica para higienização das mãos. Rev. Enferm. UFPE online., 2018; 12(2): 320-8.

9. FREITAS TSC. Implementação de ações inovadoras fundamentadas na estratégia multimodal: plano de ação para higienização das mãos. Dissertação (Mestrado Profissional em Enfermagem Assistencial) - Escola de Enfermagem Aurora de Afonso Costa, Niterói, 2017; 93 p.

10. GRAVETO JMGN, et al. Higiene das mãos - adesão dos enfermeiros após processo formativo. Rev. Bras. Enferm., 2018; 71(3): 1189-1193.

11. GUARANA CVPS, et al. Avaliação da Competência de Estudantes de Medicina em Identificar Riscos à Segurança do Paciente através de Simulação. Rev. Bras. Educ. Med., 2019; 43(1): 431-439.

12. OLIVEIRA FJ, et al. Avaliação das práticas de adesão à higienização das mãos relacionadas com linhas vasculares em uma Unidade de Terapia Intensiva. Vigilância Sanitária em Debate, 2016; 3(4):55-61.

13. OLIVEIRA AC, et al. Adesão a higienização das mãos entre técnicos de enfermagem em um hospital universitário. Ver. Enferm. UERJ, 2016; 24(2).

14. Principais itens para relatar Revisões sistemáticas e Meta-análises: A recomendação PRISMA. Epidemiol. Serv. Saúde, 2015; 24(2): 335-342.

15. PRADO MF, HARTMANN TPS, TEIXEIRA FILHO LA. Acessibilidade da estrutura física hospitalar para a prática da higienização das mãos. Esc. Anna Nery, Rio de Janeiro, 2013; 17(2): 220-226.

16. ROMERO DMP, et al. Efeitos da implementação de um programa de educação de higienização das mãos entre profissionais de uma UTI: análise de séries temporais interrompidas. J. Bras. Pneumol., 2019; 45(5).

17. SANTANA-CAIRES M, et al. Avaliação das Práticas de Higienização por Estudantes de Medicina da Universidade Federal da Bahia (Brasil) durante Atendimento Clínico. Rev. Bras. Educ. Med., 2016; 40(3): 411-422.

18. SILVA VD, et al. Avaliação da higienização das mãos de acadêmicos de Enfermagem e Medicina. Rev. RENE, 2017; 18(2): 257-263.

19. ŠKODOVÁ M, et al. Avaliação da qualidade da técnica de higiene das mãos em alunos de enfermagem e medicina em dois cursos de graduação. Revista Latino-Americana De Enfermagem, 2015; 23(4): 708-717.

20. SOUZA LM, et al. Adesão dos profissionais de terapia intensiva aos cinco momentos da higienização das mãos. Rev. Gaúcha Enferm., 2015; 36(4): 21-28.

21. ZOTTELE C, et al. Adesão dos profissionais de saúde à higienização das mãos em pronto-socorro. Rev. Esc. Enferm. USP, 2017; 51 . 